\title{
DEL CUERPO COMO PRESENCIA AL CUERPO COMO AUSENCIA*
}

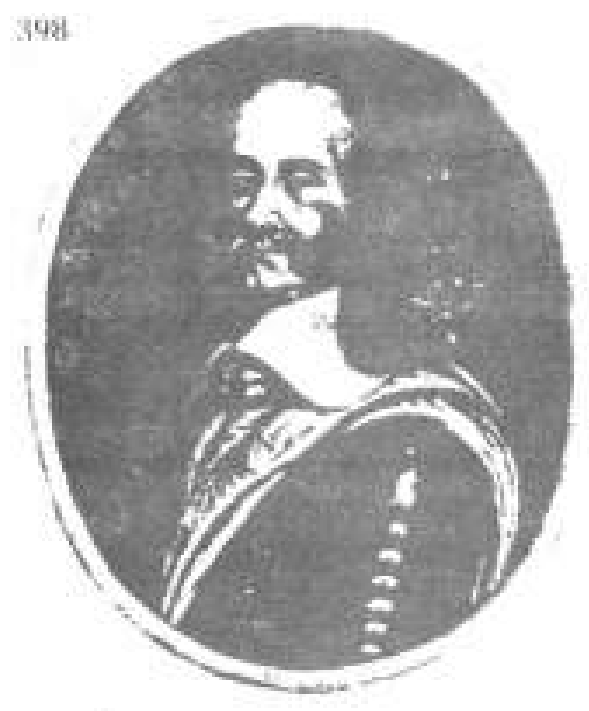

Vivir cada día como si fuese el último es un suen̄o pesado y además imposible.

El hombre es por definición futuro, promesa, elemidad fugak.

$\mathrm{Y}$ un bombre no es uno sino lodos los hombres.

Con cada nacimiento

Con ciada muente

La especie entera se está jugando su destino

Mi vida no es en realidad mi victa

No me perienece nada de lo que llarno mio

Mi came?

Extá bien, mi carne es mía

Pero, y quien dice que esa es su came jesta señalando al po que tiene al frente de sus ojos?

No

Es la propia came la que se llima asi misma como miu

¿Yo soy mi carne?

La ceneza de pseer mi came recide en la propia paiabra yue la está nombrando como mía

La palabra es el dueño de todo lo que existe.

Adolfo Grisales

ADOLFO LEONN GRISALES VARGAS

Fillósofo, Magister

Profesor Catedrático Departamento de Ciencias Hamanas

Universidad Autónoma de Manizales

Profesur Universialad de Caldas 
S t ha vuelto usual desde ta Modernidad pensar nuestro cuerpo como maiquina. Es frecuente ver programas didácticos sobre la prodigpiosa máquina del cuerpo humano; ta medicina además, suele pensarnos desmembrados, por piezas que pueden reemplazarse cuando dejan de funcionar; y en el campo de la computación se sueria con reducir a máquina to que pareceria irteductible: $b$ inteligencia

Hubo un tiempo en el que los: homberes se preguntaban con insistencia: ¿qué nos diferencia de los animales? Hoy, en su lugar, la pregunta suele ser: equé nos diferencia de las máquinas? La primera pregunta suponia el asombro frente a un mundo lleno del prodigio de la vida, donde los hamanos nos sabiamos y nos sentiamos uno más entre li exuberancia de la vida, acaso la más inteligente o la más perfecta de las formas vivas, pero forma viva al fin $y$ at cabo. Hoy, en cambio, y no lo digo con nostalgia, el cosmos entero es visto como una máquina enorme, y nosotros, a su vez, nos vemos como una máquina entre las máquinas, y nuestra diferencia parece consistir justo en bo que nos hace defectuosos como máyuna: la sensibitidad. Mas al lado de esat mecanización del cuerpo operada en la Modernidad, encontramos. orro cambio más profundo en la experiencia de nuestro cuerpo, que podriamos llamarla brevemente la inesencalidad del cuerpo, de donde se desprenden dos posturas que, en apariencia opuestas, estín apoya- das lo mismo: el ahandono o descuido del cuerpo y estetización o desplazamiento de nuestro ser 2 la exterioridad individualizada del cuerpo.

Pensar el cuerpo cotno maquina nos abre dos interrogantes. El primero edesde dónde se juzga la eficiencia, funcionahidad y adecuación de la máquina humana? En el caso de las otras màquinas estos tres fsictoren se miden desde su vinculación con el hombre. Asi, pot ejemplo, que eu unss tijens haya casi una perfecta adecuación entre lo que son y lo que parecen, depende ea buena medicia de la disposición y forma de nuestra mano. En cambio, y este seria ef segundo interrogante, ecuál es el referente desde dande diremon que aquello que somos y lo que parecemos; se adecúan? Utan posibiliclad seria que dicho referente fuera Dios, pues la Biblia dice que fuimos hechos a imagen y semejanza de Dios, en cuyo caso nuestra perfección dependeris, digsmos, de la Teometria, ari como en los objetos depende en buena parte de su antropometria. Otra alternativa, aunque más incomoda pero real, son las máquinas mismas, es decir, nuestra perfección se juzgaria de acuerdo con nuestra, llamémosla, maguinabilidad o nuestra capacidad de set uno con la máquina. Esta úlrima opción supone una circularidad que, st bien es absurda, es la que configura nuestro entorno: la máquna, su movilichad y productividad son el referente úlumo Se trata de la movilidad y productividad 
como fines en si mismos, poco importa qué, para qué o para quién, lo único es que no se puede detener. Todo atentado a la movilidad es herejia: se construyen puentes peatonales y viaductos, se reducen andenes y parques para que nada pueda afectar la fluidez del movimiento. $Y$ ello abarca, por supuesto, la propia movilidad del cuerpo: la disfuncionalidad en el movimiento supone, en la experiencia originaria de quien la sufre, algo asi como la muerte, el marginamicnto con relación al engranaje general. Claro que el otro extremo de lo mismo es el Domingo de la máquina.

Del lado de lo que hemos denominado inesentiabidad del saerpo, que es afin a lo anterior, encontramos otros intertogantes. Pero precise. mos primero el concepto. De modo esquemático cabria decir que, en una perspectiva a mitad de camino entre la hermenéutica y la semiótica, habria varias formas de asumir el cuerpo en términos de la relaciòn significado-significante. La primera seria la simbólica, en donde la conciencia desborda los limites del cuerpo: lo que el hombre sabe $y$ cree de sí mismo no cotncide con las fronteras del cuerpo. Su cuerpo, en rigor, no es su cuerpo: él es en y con orros cuerpos. Me refiero a los hombres de las primerns culnuras (quizá a los primeros años del indrviduo). Si aquí cupiera hablar en nuestro sen- tido de cuerpo, habria que decir que, siendo la conciencia una conciencia colectiva, también el cuerpo es colectiva $Y$ si pensamos h forma simbólica con ralación al indrividuo, habria que asumir al cuerpo como mensajero de los dioses.

La segunda forma podriamos denominarla, siguiendo las claves hegelianas con referencia al arte, la forma clásica. Aqui la conciencia viene a concondar puntualmente con el cuerpo: el saber de sí coincide con el reconocimiento de. las fronteras de su cuerpo, el hombre se indrvidualiza. Mientras en la forma simbólica el significante rebasa el significado, en la forma clásica significante y significado se funden. El ser humano es aquello que partect ser. El cuerpo no es apenas una forma confusa de referir a lo que somos, er lo que somos. En el desarmollo de la culrura, el cjemplo pot excelencia seria el pueblo griego. En términos de lo divino, el cuerpo ya no es el mensajero, es la aparición misma de lo divino.

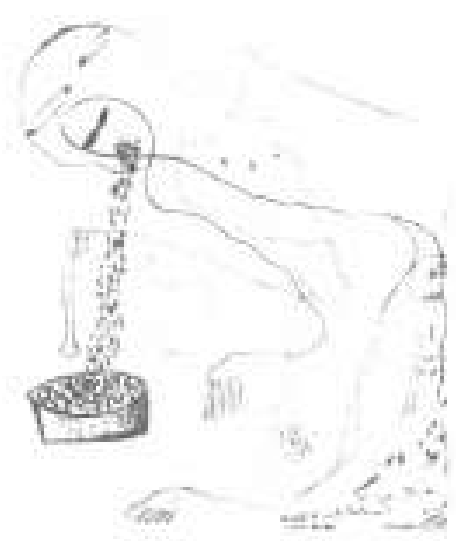

La tercera forma es is del cuerpo como representación. Bajo esta forma accedernos propiamente al cuerpo como inesencial. Aquí nue: vamente encontramos una inadecuación entre lo que somos y lo que parecemos como en la forma simbólica, pero en este caso es, en cambio, el rignificado el que rebasa al significante, es decir, la conciencia de si se ha individnalizado tanto que frente a ella el propio cuerpo no es más que un agtegado de partes, una forma de referir $o$ de remitir a lo que soy, pero definitivamente lo que soy no coincide con ninguna de las partes.

Es en esta última disociación que descansa la mecanización del cuerpo. Éste ya no es simbolo ni es una forma de aparición de lo divino: el cuerpo deviene signo, lo divino deshabita por completo la presencia; ya no es ni el measajeto de los dioses ni su aparición, sino recuendo, un temint a lo ausente. La relación significadosignificante es univoca a diferencia de la forma simbólica. Sin embargo, eso que somos ya no es un cuerpo sino una idea, y el cuerpo es una manera de decir esa idea que somos, pero, como con todo signo, no cabe la ingenuidad de confundir el signo con lo representada.

La úlrima forma es la del cuerpo como imagen. I a configuración interior se sustentaba en la creen- 
cia de que en efecto habia un referente, algo era referido con el cuerpo El cuerpo como imagen, en cambio, implica un profundo nihilismo, para decito analogando a Nuetzsche, la "muerte del significado". Lo que somos se apoya en la imagen, $y$ no es disociable de su forma de manifestarse, por el contrario, son las imágenes questras las que determinan, crean y condicionan lo que somos. A diferencia de la forma ciasica, donde ser y parecer se confunden, y el ser es asumido desde su aparicoón, en esta nueva forma, en cambio, el see no tene la solidez de la presencia, sino la evanescencia de la imagen. Distinto al signo, la imagen no es un remirir o un recordar, sino el aparecer mismo de aquello a lo que se remite, aparición que sin embargo no podemos ya suponer que sea la de algo que es algo antes de que surja, y en consecuencia sea en sus amagenes. La imagen es asumir que aquello que somos no es nit una pura indeterminacion (simbolo) ni un sustrato objetivo (cuerpo clásico) ni un sustrato supetivo (cuerpo signo), es decit, no es propiamente A/go, sino scilo su imagen. Asumir el cuerpo como imagen es hacerlo desde la ligereza y evanescencia de la imagen, aprehenderio desde su propta inesencialidad. $Y$ aqui la perfección en terminos semióticos depende de la transparencia y nitidez de la imagen. La disfuncionalidad del cuerpe bene-aqui el efecto de insultar con su presencia plena, es un cuerpo que no puede ser visto desule la distancia de la imagen. Dicho de una manera abrupti, algo asi como uns silla que funciona tral y por ello nos obliga permanentemente a experimentarla como presencia, contrano a que si funcionara $\mathrm{CD}$ rrectamente, en tal caso, pasaria desapercibida como silla.

De maneru sintética podriamos decir entonces que lo que ha ocufrido en nuestra cultura es una suerte de desaparición de las pre. sencas. Del lado de los objetos, pot ejemplo, encontramos una especie de adelgazamiento de su materalidad. la cama de hace quinientos ashos era una cama pesada, "gorda" st se quiere; how, en cambix, su materialidad es como una presentación esquemitica de la idea. Ast también los cuerpos: ha habido una especie de adelgazamiento del cuerpo

Ein la imagen nuestro cuerpo y lo que somos se tejen desde la mirada del otro: el cuerpo se hace

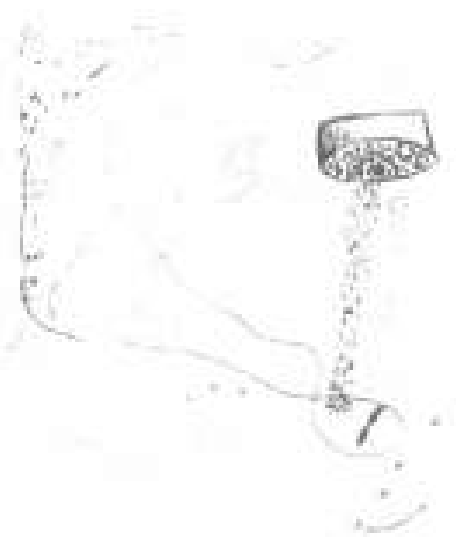

desde su visibilidad y su ser visto. Lo que somos está sostenido en un juego de espejos, por ella se vuelven difusos los limites entre lo real $x$ lo ficticio

Nuestro cuerpo pasó de fier la presencia directa de nuestro ser, a la máquina que es sut signo, sir hue lla, $y$ ha devenido fimalmente imagen. Dicho de manera muy simple, se han disuelto los limites ea. tre la real sobidez de mi cuerpo? Micky Mouse. Un critico de arte, Gombrich, decia que el nuevo mundo de ta imagen se inaugura con aquella vieja pelicula: Fantasia, donde el director de oryuesta, Stokrovsky, le da la mano a Micky Mouse. Desde entonces ya no es posibie diferenciar en el cine cuindo se trata de una imagen goe es representación; y cuándo de una que es ptopiamente imagen. Incluso va no son las caricaruras las que persiguen rasgos antropomorficos, mas bien parece a la inversa, en la calle vemos jóvenes que quieren parecer cancaturas.

Ahora bien, este ámbito de la imagen tiene su contrapunto en ba pura estetización del cuerpo. Esta es, digrimoslo asi, la versión degradada que nos invade. Cierto que la imagen es de alguin modo una apariencia plana, pero en ella es posible retener la profundidad como ausencia. Io que está ocurnendo en cambio, es que el ser 
se ha vaciado por completo de la dimensión de la ausencia y se ha reducido en su rotalidad a superficie, $y$ asi hemos ingresado en un mundo de cuerpos volcados entetamente hacia afuera, cuya imagen no es soporte y revelación mágica de la zusencia, sino una mera aperición plana.

Fsta perversión esteticista desliga la belleza de la vida. Del mismo modo que el arte abandonó los espactos vitales para refrigerarse aislado en el museo, igual la esterización del cuerpo es un arrancar la valoración de su belleza de los nexos vitales, Ser bello se ha teducido a rener cierto tamano, cierta forma, cierto color. La belleza, decia el poeta Rilke, es el limite de lo terrible que los humanos podemos soportar, es decir, la belleza es mostración y ocultación de lo inefable, de lo indecible, del misterac. Es el misteno que se exhibe pero que aún en su mosrrarse es retenido como arcano.

Bueno, pero joómo habrá que vaforar estos cambios? Quisiera insistir en que, pese al carácter en apariencia negativo de esta evolución, mi intención no es la nostal. gia. Es cierto que tal vez pudo haberse reducido nuestro cuerpo a función o a un gancho de donde cuelga poea o mucha carne, pero también es cierto que nuestro cuerpo se ha liberado. Si antes, por ejemplo, en el cabello-como soporte material- descansaba nuestra masculinidad como una de sus formas de materialización, hoy vernos en carbbio, cómojuegan los jơvenes con $\mathrm{el}$

Orna procisión. Ya para concluir. debo admitir que puede ser malinterpretada la expresión inesenciádad del anerpo. Quicro sugerir que se la entienda como que la esencialidad del cuerpo radica justamente es ser cuerpo, Fiste remite, como imagen, a algo más alla de ét, eso que somos: Sin embargo, eso que somos, en tanto retendo e "interpretado" por el cuerpo, es una creación del cuerpo

Esto puede comprenderse mejor desde una analogia. Imaginemos que una orquesta sinforica interpreca una obra de Mezart. Es cierto que dicha obra "exaste", en cierto sentido, previa a su interpreta-

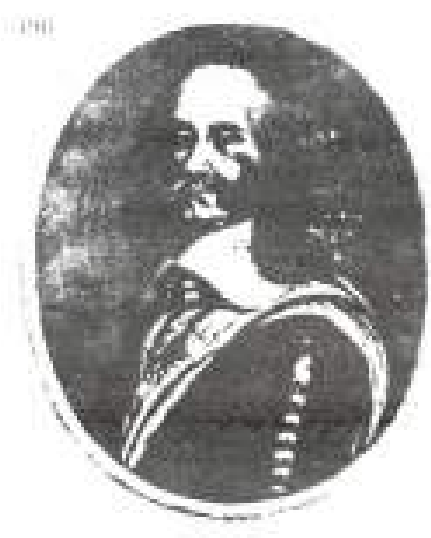

cion, pero no existe como musica, sino como sucesión de signos. Una obta musical realmente if en sus ejecuciones, y no tiene sentido preguntarse por una "interpretación" ideal, ni siquiera lo sena la que pudiera hacer el propio compositor dingnendo una orquesta. Del mismo modo cabe petisar el cuerpo como "interpretación" de lo que somos, y eso que somos sólo es en tanto comprendida por cl cuerpo. Pero equé implica esto con referencis a la disfuncionalidad corporal? Sigraifica que pensar el cuerpo desde la inmediatez de la máquina-función de la imagen estética, es seguir utrapados por uni mirada esencialista y metafisica de lo que somos, donde el cuerpo no putede. si no ser experimentado como una especie de prisión o un reflejo defectuoso del aims, de lo que verdaderamente somos. En cambio, pensar el cuerpo como interpretación desde una re-significación d el concepto de imagen, nos revela que de lo que se trata no es ni de restablecer la funcionalidad $\mathrm{ni}$ de pulir la imagen, sino de posibilicar que pueda ser interpretada, que suene esa sinfonia que somos.

- Ponencia presentada en el I Fors Nacional de Cuerpo Movimuento 